\title{
Research on "Load- Grid - Source" Collaborative Optimization Operation Considering Incremental Flexible Load Caused by Electric Power Substitution
}

\author{
WU Yahui ${ }^{\mathrm{a}}$, GUO Bingqing ${ }^{\mathrm{b}}$, JIANG Limin ${ }^{\mathrm{c}}$, HE Guixiong ${ }^{\mathrm{d}}$, LIU Kaicheng ${ }^{\mathrm{e}}$ \\ China Electric Power Research Institute \\ NO.15, Xiaoying Rd(E), Qinghe, Beijing 100192,Chinaline \\ Beijing, China \\ a'Wuyahui1018@163.com, bBq_guo@epri.sgcc.com.cn, cjianglm@epri.sgcc.com.cn, dheguixiong@epri.sgcc.com.cn, \\ eliukaicheng@epri.sgcc.com.cn
}

\begin{abstract}
Randomness and volatility of the output of the renewable energy, renewable energy consumptive become the world difficult problem. The incremental load capacity of the grid due to the implementation of the "double alternative" strategy becomes another available load side resource in the grid dispatching, in this paper, from the social point of view, to maximize the benefits of the whole society as the goal, taking into account the conventional unit incremental power generation and power grid incremental power loss costs, renewable energy incremental power consumption and different users in different grid policies to respond to power grid scheduling gains, The "load - grid - source" collaborative optimization model based on the new flexible load is established, and the validity and practicability of the model are verified by the improved PJM5 bus system. The simulation results also show that the "load - grid - source" collaborative optimization can improve the level of renewable energy consumption.
\end{abstract}

Keywords-"load - grid - source" collaborative optimization; "double alternative" strategy; Renewable energy incremental power generation; Incremental flexible load

\section{INTRODUCTION}

The load side resources and power grid interaction that provides new ideas for optimal operation of power grid and renewable energy consumption(1-3). The multi-objective source-load interaction model based on flexible load is established through collaborative optimization of power generation side and the flexible load of demand side, Considering the power generation cost of the conventional unit and the scheduling cost of the flexible load and the total amount of CO2emissions from the power generation side, The normal boundary intersection (NBI) method is used to simulate the 10-cycle 24-day study. The simulation results show the validity of the model (4). In the literature (5), the overall framework of "source-network-charge" interaction is proposed, and it is pointed out that the future flexible power system will show a variety of interactive modes such as

"Study on Economic Assessment and Control Technology of Cooperative Operation of Distributed Photovoltaic and Air Source Heat Pump” of SGCC science and technology project. complementary sources, source network coordination, grid interaction and source interaction; Literature (6) by analyzing the adjustability of the high energy-carrying enterprises, it proves the feasibility of the renewable energy consumption in the intelligent park, and combines the mixed energy and energy storage modeling in the intelligent park, the power and load are jointly scheduled which improve the local energy consumption of renewable energy.

The power grid injecting a new incremental adjustable flexible load caused by the incremental load that due to the implementation of the "double alternative" strategy. Document (8) defines the quantification calculation of the electric energy substitution implements the electric energy substitution quantity, establishes its (human impact of population affluence and Technology) IPAT model, and analyzes the potential of electric energy substitution by constructing many scenes; Document (9)propose a project to use wind power curtailment to winter heating for the problem of wind power curtailment in Zhangjiakou, through the establishment of calculation model of electric load, wind power accommodation and environmental benefit calculation model, mainly from the social and environmental benefits and the impact on the power system, verify the feasibility of the scheme.

However, the existing research is generally considered a separate flexible load, not taking into account the impact of just load, with the release of the electricity market side, more and more power users who contains the just loads, the electricity loads and the incentive loads to participate in the electricity market which rich the main body of the electricity market. Based on the "two alternatives" strategy, this paper takes the basic load as the starting point, and then deduces the new flexible load value of the power grid, and establishes the "load - grid - source" collaborative optimization model based on the new flexible load that provide a theoretical basis for the implementation of New Electricity Price Policy on Power Grid, large-scale direct purchase of electricity and bilateral transactions in China's electricity market. 


\section{TheORETICAL MODEL OF THE POWER GRID INCREMENTAL POWER LOSS}

The incremental network loss caused by the incremental load of the power network can be calculated as follows:

$$
\begin{aligned}
\Delta P_{\text {loss }}= & P_{\text {load }}-P_{\text {load }}= \\
& \sum_{j=1}^{n} \sum_{k=1}^{n} U_{j}^{\bullet} U_{k}^{\bullet} G_{j k} \cos \delta_{i j}^{\bullet} \\
& -\sum_{j=1}^{n} \sum_{k=1}^{n} U_{j} U_{k} G_{j k} \cos \delta_{j k}
\end{aligned}
$$

Consider the incremental load of the power balance equation can be written as follow:

$$
\sum_{i=1}^{n} \Delta P_{G i}-\sum_{i=1}^{n} \Delta P_{l i}-\Delta P_{\text {loss }}=0
$$

Where $\Delta P_{G i}$ is the output change of the generator, $\Delta P_{l i}$ incremental load change and $\Delta P_{\text {loss }}$ is incremental power loss.

The power grid loss can be presented as follow:

$$
P_{\text {loss }}=\sum_{j=1}^{n} \sum_{k=1}^{n} U_{j} U_{k} G_{j k} \cos \delta_{j k}
$$

From (3)we can get the Sensitivity analysis of state loss to state variables as follow:

$$
\Delta P_{\text {loss }}=\left[\frac{\partial P_{\text {loss }}}{\partial \delta^{T}}, \frac{\partial P_{\text {loss }}}{\partial U^{T}}\right]\left[\begin{array}{l}
\Delta \delta \\
\Delta U
\end{array}\right]
$$

Sensitivity Analysis of Node Injection Power to State Variables can be written as (5):

$$
\left[\begin{array}{c}
\Delta P \\
\Delta Q
\end{array}\right]=\left[\begin{array}{ll}
\frac{\partial P}{\partial \delta^{T}}, & \frac{\partial P}{\partial U^{T}} \\
\frac{\partial Q}{\partial \delta^{T}}, & \frac{\partial Q}{\partial U^{T}}
\end{array}\right]\left[\begin{array}{l}
\Delta \delta \\
\Delta U
\end{array}\right]=J\left[\begin{array}{l}
\Delta \delta \\
\Delta U
\end{array}\right]
$$

From (5) we get

$$
\left[\begin{array}{l}
\Delta P_{G}-\Delta P_{L} \\
\Delta Q_{G}-\Delta Q_{L}
\end{array}\right]=\left[\begin{array}{l}
\frac{\partial P}{\partial \delta^{T}}, \frac{\partial P}{\partial U^{T}} \\
\frac{\partial Q}{\partial \delta^{T}}, \frac{\partial Q}{\partial U^{T}}
\end{array}\right]\left[\begin{array}{l}
\Delta \delta \\
\Delta U
\end{array}\right]=J\left[\begin{array}{l}
\Delta \delta \\
\Delta U
\end{array}\right]
$$

Form(5)and(6)we can get the sensitivity of load to generator output as follow:

$$
\begin{aligned}
{\left[\begin{array}{c}
\Delta \delta \\
\Delta U
\end{array}\right] } & =J^{-1}\left[\begin{array}{c}
\Delta P \\
\Delta Q
\end{array}\right]=\left[\begin{array}{l}
\frac{\partial P}{\partial \delta^{T}}, \frac{\partial P}{\partial U^{T}} \\
\frac{\partial Q}{\partial \delta^{T}}, \frac{\partial Q}{\partial U^{T}}
\end{array}\right]^{-1}\left[\begin{array}{c}
\Delta P \\
\Delta Q
\end{array}\right] \\
& =\left[\begin{array}{l}
\frac{\partial P}{\partial \delta^{T}}, \frac{\partial P}{\partial U^{T}} \\
\frac{\partial Q}{\partial \delta^{T}}, \frac{\partial Q}{\partial U^{T}}
\end{array}\right]^{-1}\left[\begin{array}{c}
\Delta P_{G}-\Delta P_{L} \\
\Delta Q_{G}-\Delta Q_{L}
\end{array}\right]
\end{aligned}
$$

In conclusion, we get

$$
\begin{aligned}
\Delta P_{\text {loss }} & =\left[\frac{\partial P_{\text {loss }}}{\partial \delta^{T}}, \frac{\partial P_{\text {loss }}}{\partial U^{T}}\right]\left[\begin{array}{l}
\Delta \delta \\
\Delta U
\end{array}\right] \\
& =\left[\frac{\partial P_{\text {loss }}}{\partial \delta^{T}}, \frac{\partial P_{\text {loss }}}{\partial U^{T}}\right]\left[\begin{array}{l}
\frac{\partial P}{\partial \delta^{T}}, \frac{\partial P}{\partial U^{T}} \\
\frac{\partial Q}{\partial \delta^{T}}, \frac{\partial Q}{\partial U^{T}}
\end{array}\right]^{-1}\left[\begin{array}{l}
\Delta P_{G}-\Delta P_{L} \\
\Delta Q_{G}-\Delta Q_{L}
\end{array}\right]
\end{aligned}
$$

\section{DEMAND RESPONSE MODEL}

A. Price-sensitive demand response (PSDR) model First,

The PSDR of each power user is mainly based on the demand elasticity, and the relationship between the load change, the price change and the elasticity of the user's own demand can be written as follow:

$$
E_{i k s t}=\left(\Delta L_{i k s} / L_{0 i k s}\right) /\left(\Delta P_{i k t} / P_{0 i k t}\right)
$$

Where: $E_{i k s t}$ is the power demand elasticity of the user $\mathrm{k}$ in the voltage level $i$, when $s=t$ it means self-elasticity, else ,it means cross-elasticity; $L_{0 i k s}$ is the user load value before the implementation of one price policy; $\Delta L_{\text {iks }}$ is the change amount of the user's load after the implementation of one price policy; $P_{0 i k t}$ is basic electricity price policy; $\Delta P_{i k t}$ is new electricity price policy.

From Eq. (9)we can get the load changes during each period after the implementation of one price policy as follow:

$$
\left[\begin{array}{l}
\Delta L_{i k 1} \\
\Delta L_{i k 2} \\
\vdots \\
\Delta L_{i k n}
\end{array}\right]=\left[\begin{array}{llll}
L_{0 i k 1} & & & \\
& L_{0 i k 2} & \\
& & \cdots & \\
& & & L_{0 i k n}
\end{array}\right]\left[\begin{array}{ccc}
E_{i k 11} & \cdots & E_{i k 1 n} \\
& \vdots & \\
E_{i k n 1} & \cdots & E_{i k n n}
\end{array}\right]\left[\begin{array}{c}
\Delta P_{i k 1} / P_{0 i k 1} \\
\vdots \\
\Delta P_{i k n} / P_{0 i k n}
\end{array}\right]
$$

\section{B. Incentive-based demand response(IBDR) model}

IBDR, which according to the response characteristics of the project itself, such as the response amount, the response time, the response frequency and so on, and when analyzing the response characteristics of one special demand project, we can improve the response potential and efficiency through clustering analysis and then establish a mathematical model(9) In the new situation, the demand response from the traditional response model into intelligent control mode which through centralized control, distributed autonomy, and remote collaborative, with the load aggregator as the intermediary, 
which aggregate the adjustable or interruptible loads that dispersed from the geographical location, and provide ancillary services for the power system operators or large power grid through professional centralized control technology(10-11). In this paper, we take regenerative electric heating boilers as an example and build a load aggregator model. where the load aggregator is a real-time response resource.

The electric heat storage boiler mainly runs in the valley of the power, and meets the basic heat supply, at the same time meet the user's comfort requirements in other periods through the heat storage in the valley of the power. According to the indoor temperature setting value, the heat needed by the electric heat storage boiler, the load aggregator daily electricity consumption and the total heat storage capacity can be written as follows:

$$
\begin{gathered}
Q_{t}=\sum_{i=1}^{l} \sum_{j=1}^{n} q_{i} S_{i j}\left(T_{i, t-\text { in }}-T_{i, t-\text { out }}\right) \\
W=\sum_{t=1}^{24} Q_{t} / \eta_{t} \\
E=\gamma W
\end{gathered}
$$

Where: $Q_{t}$ is heating load at time period $\mathrm{t} ; q_{i}$ is the unit area heat dissipation for the i class building; $S_{i j}$ is the $\mathrm{j}$ building area for the $\mathrm{i}$ class building; $T_{i, t-i n}$ and $T_{i, t-o u t}$ are the indoor temperature setting value for the i class building and outdoor temperature at time period $\mathrm{t} ; \eta_{t}$ is electric regenerative boiler efficiency at time period $t ; \gamma$ is capacity coefficient of energy storage unit.

Demand response constraint:

$$
-\Delta L_{D} \leq \Delta L_{t} \leq \Delta L_{U}
$$

Where: $\Delta L_{D}$ and $\Delta L_{U}$ are maximum reduced and increased amount of load at time period t.

$$
-L_{D} \leq \Delta L_{t}-\Delta L_{t-1} \leq L_{U}
$$

Where: $L_{D}$ and $L_{U}$ are the maximum reduced rate and increased rate at time period $t$.

The load need to meet their own load regulation constraints when response to the power grid scheduling, i.e.:

Scheduling time constraint can be presented as follow:

$$
T_{t}-T_{t-1} \geq \Delta t
$$

In addition to the PSDR, in order to meet the load production needs, the general requirements can be presented as follow:

$$
\sum_{t=1}^{T} v_{t} \Delta L_{t, D}=\sum_{t=1}^{T} v_{t} \Delta L_{t, U}
$$

Where: $v_{t}$ is 0,1 variable.

For IBDR, the load reduction or incremental constraint throughout the scheduling period needs to meet the constraint as follow:

$$
M_{D}^{\max } \leq \sum_{t=1}^{T} \Delta L_{t} \leq M_{U}^{\max }
$$

Where: $M_{D}^{\max }$ and $M_{U}^{\max }$ are the maximum amount of load reduce and increase.

For the virtual storage of the load aggregator, because of its unique operating characteristics, the constraints can be presented as follow:

$$
\begin{gathered}
\left\{\begin{array}{l}
\mathbf{O} \leq \boldsymbol{u}_{t, \text { ch }} \leq \mathbf{1} \\
\mathbf{0} \leq \boldsymbol{u}_{t, \text { disch }} \leq \mathbf{1}
\end{array}\right. \\
\left\{\begin{array}{l}
0 \leq P_{t, c h} \leq u_{t, c h} \cdot \overline{P_{c h}} \\
0 \leq P_{t, d i s c h} \leq u_{t, \text { disch }} \cdot \overline{P_{d i s c h}}
\end{array}\right. \\
\left\{\begin{array}{c}
E(i)=E(\boldsymbol{i}-\mathbf{1})-P_{t-1, \text { disch }} \cdot \Delta t+P_{t, c h} \cdot \Delta t \\
\underline{E} \leq E(i) \leq \bar{E}
\end{array}\right.
\end{gathered}
$$

where $u_{t, c h}, u_{t, d i s c h}$ are discharging and charging mode 0-1 variables of virtual storage at time period $\mathrm{i} ; \overline{P_{t, c h}}$ and $\overline{P_{t, d i s c h}}$ are discharging and charging power upper limit of virtual storage; $\mathrm{E}(\mathrm{i})$ is the dump energy of virtual storage at the end of time period $\mathrm{i} ; \bar{E}$ and $\underline{E}$ are the upper and lower limit of dump energy of virtual storage.

\section{ESTABLISHMENT OF COOPERATIVE OPTIMIZATION OPERATION MODEL}

The gain of consumption of renewable energy incremental power generation can be written as follow:

$$
C_{x-G}\left[C_{x-G 1}, C_{x-G 2} \cdots C_{x-G n}\right]
$$


The power generation cost of the conventional unit is closely related to the power generation. In this paper, the simplified model is used to represent the marginal cost as shown in Fig. 1. The mathematical model is:
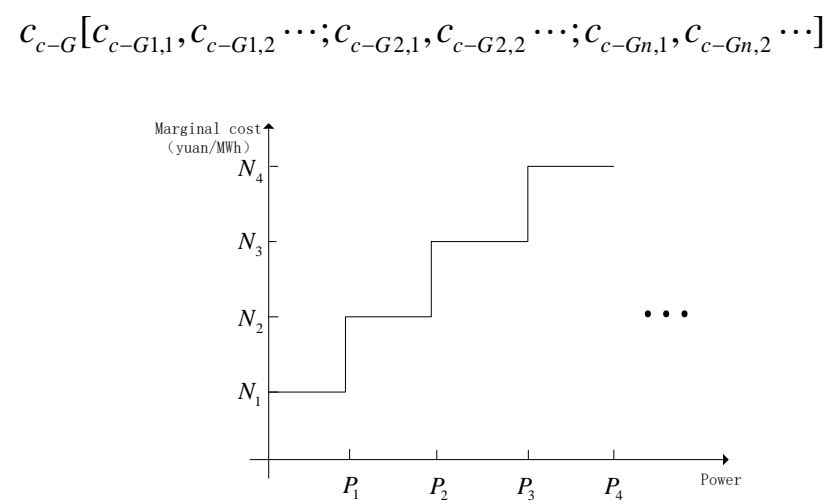

Fig. 1. The marginal cost schematic of units in different force intervals

The marginal cost of different voltage levels of power loss can be presented as follow:

$$
c_{N}\left[c_{N 1}, c_{N 2}, \cdots\right]
$$

The objective function of maximizing social benefits can be written as follow:

\section{$\max$ GS-OC}

Where GS and OC are the total income and the total cost of the whole society. The total income of the whole society includes the gains of consumption of renewable energy incremental power generation, the PSDR users and the IBDR users who participate in bilateral transactions (for example, load aggregator) that reduce the cost of electricity in the case of guaranteeing their own needs; The total social cost includes incremental power generation costs for conventional units, unit start-up costs, and the cost of incremental power losses due to incremental loads of power grid. GS and OC are calculated as follows:

$$
\left\{\begin{aligned}
\{G S= & \sum_{t=1}^{24} \sum_{i=1}^{N} c_{x-G i} \cdot \Delta P_{x-G i, t}+\sum_{t=1}^{24} \sum_{i=1}^{N}\left(\lambda_{1, t} \cdot P_{1-i, t}-\lambda_{2, t} \cdot P_{2-i, t}\right) \\
& +\sum_{t=1}^{24} \sum_{i=1}^{N}\left(\lambda_{1, t} \cdot P_{3-i, t}-\lambda_{2, t} \cdot P_{4-i, t}-\lambda_{3, t} \cdot P_{5-i, t}\right) \\
O C= & \sum_{t=1}^{24} \sum_{i}^{N}\left(c_{c-G i} \cdot \Delta P_{c-G i, t}+\mathrm{u}_{G i, t} \cdot\left(1-\mathrm{u}_{G i, t-1}\right) \cdot \mathrm{SU}_{G i, t}\right)+\sum_{t=1}^{24} \sum_{i}^{n} c_{N-i} \cdot \Delta P_{l o s s-i, t}
\end{aligned}\right.
$$

Where: $\Delta P_{x-G, t}$ and $\Delta P_{c-G, t}$ are the incremental power generation consumption of the renewable energy and the change of the output capacity of the conventional unit at time period t; $\Delta P_{\text {loss }-i, t}$ is the incremental network loss of different voltage levels at time period $\mathrm{t} ; \lambda_{1, t}$ and $\lambda_{2, t}$ and $\lambda_{2, t}$ are the conventional electricity price, the new electricity price and wind power heating price at time period $t ; P_{1-i, t}$ and $P_{2-i, t}$ are the power load before and after the implementation of the new electricity price policy for PSDR user at time period $t ; P_{3-i, t}$ is the power load before the implementation of the new electricity price policy for IBDR user at time period $\mathrm{t} ; P_{4-i, t}$ and $P_{5-i, t}$ are the power loads powered by conventional unit and renewable energy after the implementation of the new electricity price policy for IBDR user at time period t; $u_{G i, t}$ and $\mathrm{SU}_{G i, t}$ are the start-up state and start-up cost of conventional unit at time period $\mathrm{t}$.

The constraints are as follows:

(1) Power balance constraint can be written as follow:

$$
C_{N}\left[C_{N 1}, C_{N 2}, \cdots\right]
$$

(2) Unit output constraints can be written as follow :

$$
\begin{aligned}
& \Delta P_{c-G i, t}^{\min } \leq \Delta P_{c-G i, t} \leq \Delta P_{c-G i, t}^{\max } \\
& \Delta P_{x-G i, t}^{\min } \leq \Delta P_{x-G i, t} \leq \Delta P_{x-G i, t}^{\max }
\end{aligned}
$$

(3) Unit positive and negative rotation reserve constraints can be written as follow :

$\sum_{i=1}^{N} P_{c-i, t}^{\max } \geq\left(\sum_{i=1}^{N}\left(P_{2-i, t}+P_{4-i, t}+P_{5-i, t}\right)\right) \cdot(1+L \%)+\left(\sum_{i=1}^{N} P_{x-G i, t}\right) \bullet u_{x} \%$
$\sum_{i=1}^{N} P_{c-i, t}^{\min } \leq\left(\sum_{i=1}^{N_{h}}\left(P_{2-i, t}+P_{4-i, t}+P_{5-i, t}\right)\right) \cdot(1-L \%)-\left(P_{x}-\sum_{i=1}^{N} P_{x-G i, t}\right) \bullet d_{x} \%$

Where: $P_{c-G_{i, t}}^{\max }$ and $P_{c-G_{i, t}}^{\min }$ are the maximum and minimum technical output of the conventional unit at time period $\mathrm{t} ; L \%$ is positive and negative demand factor for the total load of the system; $u_{x} \%$ and $d_{x} \%$ are positive and negative demand factor for the prediction error of wind power and photovoltaic respectively; $P_{x}$ is the total installed capacity of renewable energy.

(4) Conventional unit climbing rate constraint can be written as follow:

$$
-d_{i} T_{t} \leq P_{c-G i, t}-P_{c-G i, t-1} \leq u_{i} T_{t}
$$

Where: $d_{i}, u_{i}$ are the decline and rise climb rate; $T_{t}$ is scheduling time scales.

\section{CASE STUdY}

\section{A. Basic data}

Based on the PJM5-bus system, which assumed that the wind power generator is added to the bus E, and the model proposed in this paper is validated by sensitivity analysis and real number genetic algorithm. The improved PJM5-bus 
system structure is shown as fig.2, the system contains five conventional units, a wind turbine, three load nodes, which the incremental loads of bus B belongs to the IBDR user, the load demand is $50 \mathrm{MW}$, the heat storage capacity is $300 \mathrm{MWh}$, the maximum charging and discharging load is 25MW, wind power heating price is 150 Yuan/MWh; The incremental loads of bus $C$ belongs to the PSDR user, and the catalog price is600 Yuan/MWh before the implementation of the new electricity policy, after the TOU policy, the time-interval of peak-valley price are shown in Table 1, peak and valley power price were increased and reduced by $25 \%$, the demand elasticity matrix of such user is:

$$
E=\left(\begin{array}{ccc}
-0.25 & 0.11 & 0.24 \\
0.20 & -0.25 & 0.17 \\
0.25 & 0.19 & -0.25
\end{array}\right)
$$

TABLE I. PERIOD DIVISION OF TOU

\begin{tabular}{|c|c|c|c|}
\hline period & Valley period & Flat period & Peak period \\
\hline \multirow{3}{*}{ time } & & $08: 00-10: 00$ & \\
& & $16: 00-18: 00$ & $15: 00: 00$ \\
& & $21: 00-23: 00$ & \\
\hline
\end{tabular}

In this paper, the standby demand coefficient of the wind turbine is 0.15 , and the positive and negative reserve factor of the load is 0.04 . The increased cost of the conventional units and the gain of consumption of renewable energy incremental power generation in the system are shown in Fig. 3. The power generation curves of generators and load curves are shown in Fig. 4. and the sensitivity coefficients are shown in Table 2.

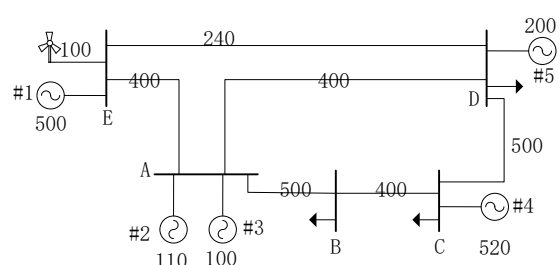

Fig. 2. Network configuration of PJM5-bus system

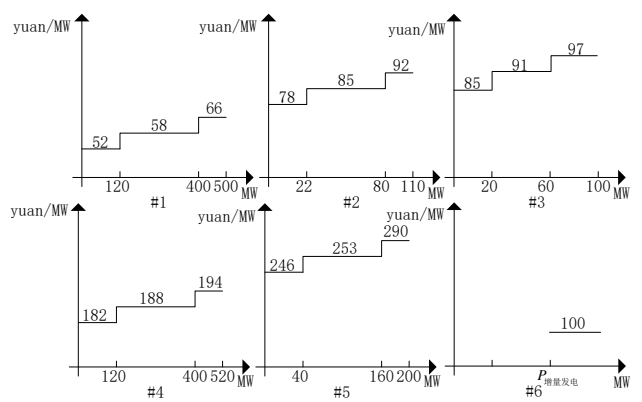

Fig. 3. Schematic diagram of unit incremental cost

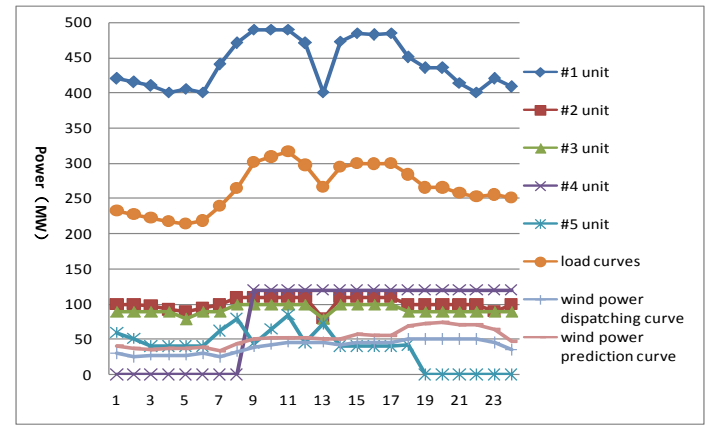

Fig. 4. Schematic diagram of units and loads

TABLE II. THE SENSITIVITY COEFFICIENT OF EACH NODE TO THE LINE

\begin{tabular}{|c|c|c|c|c|c|}
\hline $\mathbf{N L}$ & $\mathbf{A}$ & $\mathbf{B}$ & $\mathbf{C}$ & $\mathbf{D}$ & $\mathbf{E}$ \\
\hline $\mathbf{A B}$ & 0.54 & -0.13 & 0 & 0.35 & 0.51 \\
\hline $\mathbf{B C}$ & 0.54 & 0.87 & 0 & 0.35 & 0.51 \\
\hline $\mathbf{E A}$ & -0.21 & -0.06 & 0 & 0.16 & 0.68 \\
\hline $\mathbf{A D}$ & 0.25 & 0.07 & 0 & -0.19 & 0.17 \\
\hline $\mathbf{C D}$ & -0.46 & -0.13 & 0 & -0.65 & -0.49 \\
\hline ED & 0.21 & 0.06 & 0 & -0.16 & 0.32 \\
\hline
\end{tabular}

B. Analysis of "Dutch - net - source" Cooperative Operation Optimization Based on Demand Response

After the implementation of new electricity price policy and electric heating incremental load to participate in the direct purchase of electricity, The load curve of each node shown in Fig.5; conventional unit output curve shown in Fig.6; the consumption of renewable energy incremental power generation caused by direct purchase of electricity is shown in Fig.7, the whole social income is 215045 yean.

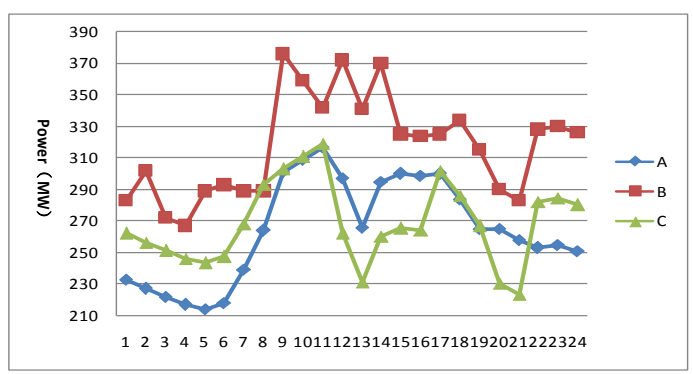

Fig. 5. Load curve of each node after optimization

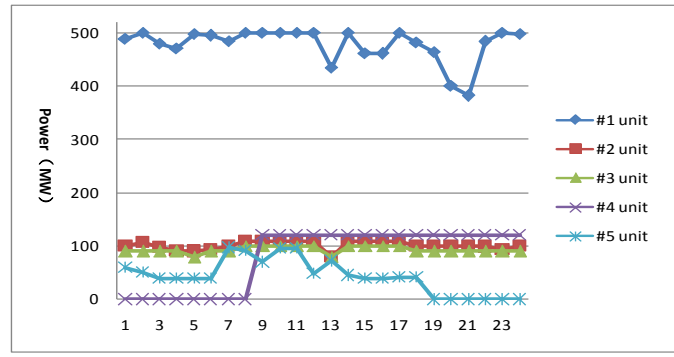

Fig. 6. The output curve of the conventional units after optimization 


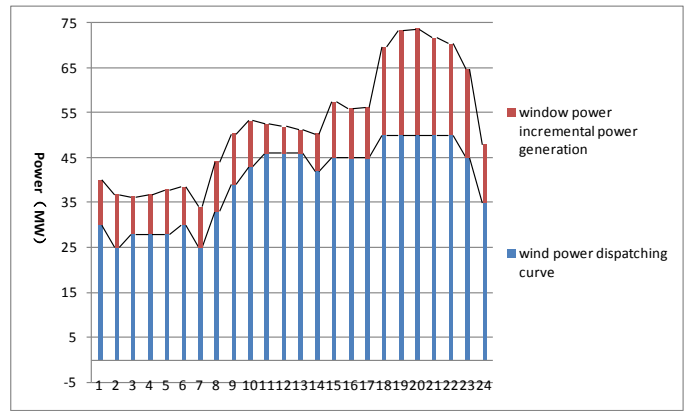

Fig. 7. The Schematic diagram of the renewable energy increment generated power consumption caused by direct purchase of electricity

From Fig. 4, Fig. 6 and Fig. 7, we get:

The virtual energy storage characteristic of the the incremental load caused by electric energy instead and the emergence of the direct purchase electricity transaction mode in the electricity market provide more choice for the renewable energy consumption;

By digging more adjustment resources of demand side to participate in grid interaction, consider the impact of loadsource interaction on the power grid, coordinated control "load - grid - source", which can achieve maximum social benefits through maximize the use of social resources.

\section{CONCLUSION}

This paper put forward a method of "load - grid resource" joint optimization operation modeling, which from the social point of view, to maximize the benefits of the whole society as the goal, taking into account the conventional unit incremental power generation and power grid incremental power loss costs, renewable energy incremental power consumption and different users in different grid policies to respond to power grid scheduling gains, Using the sensitivity analysis method, considering the new grid policy and the new situation, optimizing the incremental load of the power grid, through the typical example analysis we can get the following conclusions:

Load aggregator as a virtual storage, improving the efficiency of adjustable load response to grid scheduling by aggregating more adjustable loads, and providing ancillary services to the optimized operation of the grid;
Considering the adjustable characteristics of the incremental load of the power grid, use the sensitivity analysis method, and carry out the "load-net-source" joint optimization based on the incremental load of the power grid and fully exploits the dispatchable value of the incremental load of the power grid, improve the energy consumption of the renewable energy and achieve the goal of maximizing the benefits of the whole society.

\section{REFERENCES}

[1] YANG Shengchun,LIU Jiantao,YAO Jianguo,et.al. Model and Strategy for Multi-time Scale Coordinated Flexible Load Interactive Scheduling[J]. Proceedings of the CSEE, 2014, 34(22):3664-3673.

[2] YANG Nan,WANG Bo,LIU Dichen,et.al. An Integrated Supply-demand Stochastic Optimization Method Considering Large-scale Wind Power and Flexible Load[J]. Proceedings of the CSEE, 2013, 33(16):63-69.

[3] LU Jinling,YU Huimin,YANG Jin.Stochastic Scheduling Strategy Considering Wind Power Dependence Structure and MotivationCompensation Mechanism of Flexible Load[J].Power System Technology, 2017, 41(6):1793-1800.

[4] WANG Han,XU Xiaoxiao,YAN Zheng.Multi-objective Optimization of Security Constrained Unit Commitment Model and Solution Considering Flexible Load[J].Power System Technology, 2017, 41(6):1904-1911.

[5] Yao jianguo,Yang shengchun,Wang ke,Yang zhenglin,et al.Concept and research framework of smart grid "source-grid-load"interactive operation and control[J].Automation of Electric Power Systems,2012,36(12):1-6.

[6] LI Ming,HU Diangang,ZHOU Youxue,Research and Practice of Renewable Energy Local Consumption Mode in Gansu Province Based on "Double Alternative” Strategy[J].Power System Technology,2016, 40(10):2991-2997.

[7] SUN Yi ,ZHOU Shuang ,SHAN Baoguo , et al. Analysis of Electeic Power Alternative Potential Under Multi-Scenario[J]. Power System Technology, 2017, 41(1):118-123.

[8] He Huimin, Wang Haiyan, Ren Jie,et al. Study on Wind Power Accommodation by Using Curtailed Wind Power to Heat for Power Alternative[J]. North China Electric Power, 2016(1):1-5.

[9] TIAN Shi ming, WANG Beibei, ZHANG Jing. Key Technologies for Demand Response in Smart Grid[J]. Proceedings of the CSEE: 2014, 34(22):3576-3589.

[10] GAO Ciwei,LI Qianyu, LI Huixing,et.al. Methodology and Operation Mechanism of Demand Response Resources Integration Based on Load Aggregator[J]. Automation of Electric Power Systems, 2013, 37(17):7886.

[11] SUN Yi,XU Peng,SHAN Baoguo,QI Bing.Road Map for "Internet Plus”Energy Substitution in Electricity Retail Market Reform in China[J].Power System Technology, 2016, 40(12):3648-3654. 